\title{
SIFAT FISIK DAN MEKANIS PAPAN SEMEN BERBAHAN BAKU BAMBU
}

\author{
Physical and Mechanical Properties of Cement Board made from Bamboo \\ Suhasman $^{凶}$ dan Bakri \\ Lab. Pemanfaatan dan Pengolahan Hasil Hutan, Fakultas Kehutanan Universitas Hasanuddin \\ JI. Perintis Kemerdekaan Km. 10 Tamalanrea, Makassar 90245
}

\begin{abstract}
Fire resistance, termite resistance, and high dimensional stability are among critical attributes of cement board composite as alternative material to replace solid wood products. This study aimed to evaluate characteristics of cement boards made from various age classes of bamboo (1-2 year old, 3-4 year old, and 5-6 year old) and nature of bamboo stem (used and fresh bamboo). Cement board was produced with target density of $0.9 \mathrm{~g} \mathrm{~cm}^{-3}$, and $30 \mathrm{~cm}$ $\times 30 \mathrm{~cm} \times 1 \mathrm{~cm}$ in dimension and the results showed that cement board made from younger bamboo (1-2 year old) had better physical and mechanical characteristics than cement board made from the older bamboo. Most of physical and mechanical characteristics, except for modulus of rupture and dimensional stability, of cement board made from younger bamboo fulfill the Japanese Industrial Standard (JIS) A 5417-2003. The results also showed that cement board made from used bamboo had similar characteristics with cement board made from fresh bamboo.
\end{abstract}

Key words: Young bamboo, used bamboo, cement board

\section{PENDAHULUAN}

Salah satu produk berbahan baku kayu atau bahan lignoselulosa lainnya yang memiliki sejumlah keunggulan adalah papan semen. Selain tahan api dan agen biodeteriorasi, produk ini juga memiliki stabilitas dimensi yang tinggi. Oleh karena itu pengembangan produk papan semen sebagai alternatif pengganti kayu solid perlu terus dilakukan. Akibat keterbatasan bahan baku, pengembangan pemanfaatan bahan baku bukan kayu semakin penting dan mendesak dilakukan untuk mensubtitusi penggunaan kayu. Pengembangan papan semen di Indonesia sangat potensial karena produk tersebut dapat dibuat dengan memanfaatkan kayu dan bukan kayu. Kelebihan ini didukung oleh besarnya kapasitas produksi semen di Indonesia yang mencapai 60 juta ton pada tahun 2012 dan diproyeksikan terus meningkat menjadi 75 juta ton pada tahun 2015 (Kementerian Pekerjaan Umum, 2013). Berdasarkan keunggulan komparatif tersebut,

Diterima: 30 Mei 2012; Disetujui: 29 Agustus 2012

$\square$ Penulis korespondensi (corresponding author): suhasman@yahoo.com pengembangan papan semen perlu lebih diarahkan pada pemanfaatan bahan baku bukan kayu seperti halnya bambu.

Bambu merupakan bahan baku alternatif yang sangat menjanjikan karena ketersediaannya yang melimpah di negara tropis seperti Indonesia, pertumbuhannya sangat cepat, serta mudah dibudidayakan (Muin et al., 2006). Di Indonesia, terdapat sekitar 65 species dan 9 genus bambu (Widjaja, 1980) dan tumbuh pada lahan seluas \pm 700.000 ha (Muin et al., 2006). Jenis-jenis bambu yang populer di setiap kelompok masyarakat bervariasi. Di Sulawesi Selatan, bambu yang paling populer adalah bambu parring (Gigantochloa atter) dan bambu betung (Dendrocalamus asper). Kebanyakan bambu-bambu tersebut digunakan sebagai scaffolding atau peruntukan non permanen lainnya dengan nilai ekonomi yang rendah (Muin et al., 2006). Untuk memaksimalkan nilai tambah bambu, sangat penting untuk mengembangkan pemanfaatan bambu untuk tujuan lain dengan nilai ekonomi yang lebih tinggi, misalnya pemanfaatan bambu sebagai bahan baku papan semen. Papan semen memiliki potensi nilai ekonomi yang lebih tinggi karena dapat dimanfaatkan untuk tujuan 
penggunaan jangka panjang seperti dinding, lantai, langit-langit, serta dapat pula digunakan sebagai komponen eksterior karena tahan kelembaban yang tinggi.

Beberapa peneliti telah menganalisis karakteristik papan semen bambu seperti Ling et al. (2000), Sukartana et al. (2000), serta Sulastiningsih et al. (2000). Meskipun demikian belum tersedia informasi tentang pengaruh umur bambu terhadap karaktersitik papan semen. Bambu dapat mencapai ukuran maksimal pada umur 1 tahun namun proses pembentukan ekstraktif masih terus berlangsung pada umur yang lebih tua. Karenanya bambu yang digunakan untuk tujuan konstruksi biasanya dipakai pada usia yang lebih tua (minimal 2 tahun). Namun demikian, untuk tujuan penggunaanya sebagai bahan baku papan semen, umur 1 tahun kemungkinan sudah dapat dimanfaatkan sehingga mempersingkat daur tebang. Penelitian ini ditujukan untuk menganalisis sifat fisik dan mekanis papan semen berbahan baku bambu yang berasal dari kelompok umur yang bervariasi.

\section{METODE PENELITIAN}

Bahan utama yang digunakan adalah 2 jenis bambu yaitu bambu ater dan bambu betung yang diperoleh dari Maros dan Gowa, Sulawesi Selatan. Bambu yang digunakan terdiri atas 4 kelompok yaitu bambu muda (umur 1-2 tahun), bambu dewasa (umur 3-4 tahun), bambu tua (umur $>4$ tahun), serta bambu bekas pakai yang merupakan bekas penggunaan sebagai scaffolding. Target

D $\mathrm{BM} \boldsymbol{\mathrm { BD }} \boldsymbol{\mathrm { B }} \mathrm{BT} \boldsymbol{\mathrm { BB }}$

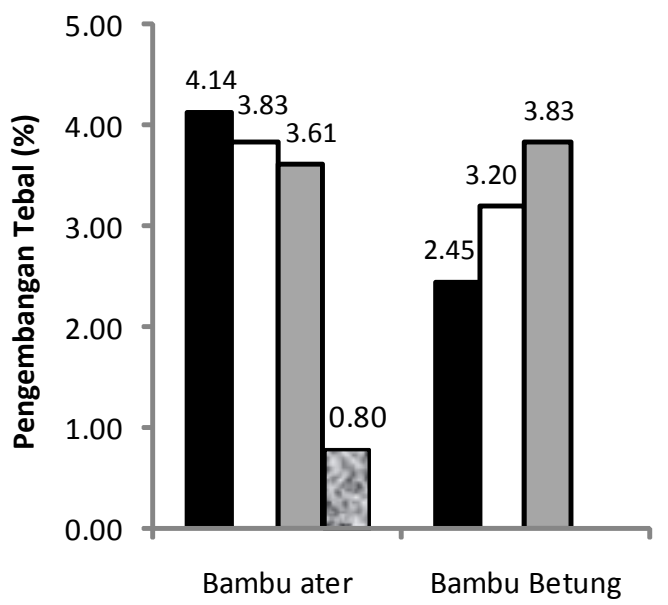

Keterangan: BM (bambu muda), BD (bambu dewasa), BT (bambu tua), BB (bambu bekas)

Gambar 1. Pengembangan tebal papan semen kerapatan papan yang dibuat adalah $0,9 \mathrm{~g} \mathrm{~cm}^{-3}$. Rasio semen dan bambu yang digunakan dalam pembuatan papan semen adalah 1,5:1. Selain itu digunakan pula bahan tambahan berupa $\mathrm{CaCl}_{2}$ sebesar $2 \%$ berdasarkan berat semen. Dalam pembuatan papan semen ini, serpih bambu segar dikonversi menjadi partikel dengan menggunakan hammer mill dan selanjutnya dikondisikan sampai mencapai kadar air pada kisaran 30-50 \%. Partikel bambu kemudian disemprot dengan air dan $\mathrm{CaCl}_{2}$ lalu dicampur dengan semen. Campuran tersebut kemudian dibentuk menjadi lembaran lalu dikempa dingin dan diklem selama 24 jam (setting process). Setelah proses setting, klem dilepaskan dan papan dikeluarkan dari plat press. Papan lalu dikondisikan pada kondisi ruangan selama 4 minggu untuk proses curing. Setelah proses curing, masingmasing papan dipotong menjadi contoh uji dengan merujuk pada Japanese Industrial Standard (JIS) A 5908-2003 (JSA, 2003b).

\section{HASIL DAN PEMBAHASAN}

Sifat fisik dan mekanis papan semen disajikan pada Gambar 1-4. Papan semen yang dibuat dari bambu ater memiliki stabilitas dimensi yang lebih rendah dibandingkan dengan bambu betung pada kelompok umur muda yang ditunjukkan oleh tingginya pengembangan tebal pada papan tersebut. Pengembangan tebal papan semen dari bambu ater cenderung turun seiring dengan peningkatan umur bambu yang diindikasikan oleh lebih rendahnya pengembangan tebal pada papan semen dari kelompok umur bambu dewasa dan bambu tua. Sebaliknya, pengembangan tebal papan semen

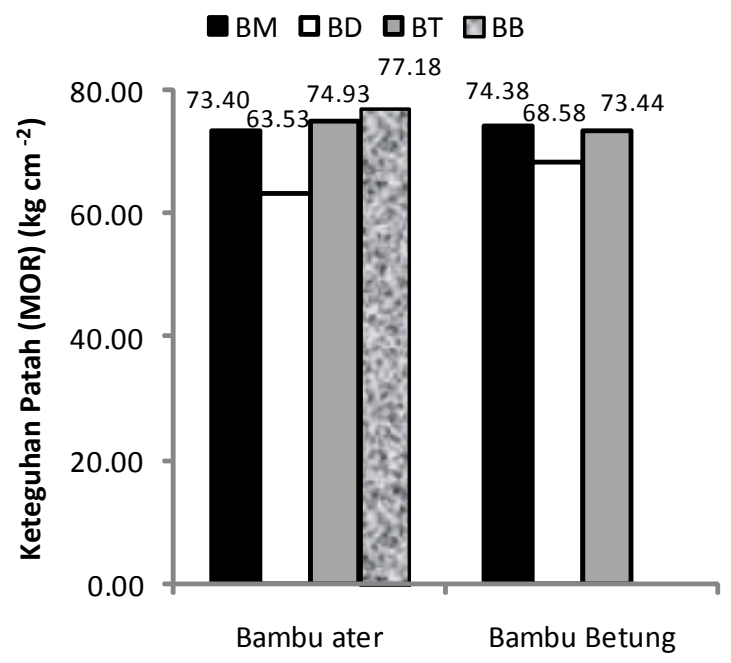

Gambar 2. Keteguhan patah (MOR) papan semen 
$\square \mathrm{BM} \square \mathrm{BD} \square \mathrm{BT} \square \mathrm{BB}$

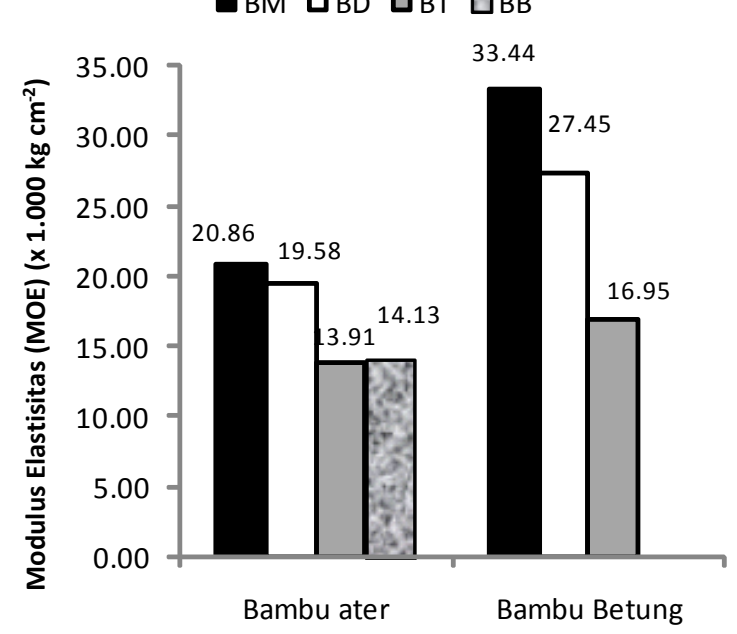

Gambar 3. Modulus elastisitas (MOE) papan semen

dari bambu betung cenderung meningkat pada saat umur bambu bertambah. Meskipun demikian, secara keseluruhan dapat disimpulkan bahwa papan semen dari bambu betung memiliki stabilitas dimensi yang lebih tinggi dibandingkan dengan papan semen dari bambu ater. Hal menarik lainnya dalam parameter pengembangan tebal ini adalah tingginya stabilitas dimensi papan semen dari bambu ater bekas. Bambu bekas telah ditebang selama beberapa bulan sehingga cukup kering. Tampaknya, proses hysteresis akibat mengeringnya bambu selama penggunaan membuat bambu ini tidak dapat menyerap air dalam jumlah yang banyak. Hal ini tampaknya berimplikasi terhadap pengembangan tebal papan semen yang lebih rendah.

Data pada Gambar 2 menunjukkan bahwa bambu dewasa memiliki keteguhan patah paling rendah dibandingkan kedua kelompok umur lainnya, sementara bambu muda dan bambu tua memiliki nilai keteguhan patah yang relatif sama. Hal ini kemungkinan disebabkan tingginya kadar pati pada tahapan umur dewasa tersebut dibandingkan kedua kelompok umur lainnya. Kadar pati yang tinggi ini dapat menjadi faktor penghambat proses pengerasan semen.

Pada parameter modulus elastisitas (MOE), terdapat kecenderungan penurunan nilai $\mathrm{MOE}$ seiring dengan peningkatan umur bambu. Hal ini berarti bahwa kekakuan papan semen akan lebih rendah apabila bambu yang digunakan sebagai bahan baku adalah bambu yang berumur tua. Oleh karena itu direkomendasikan agar bambu yang digunakan sebagai bahan baku pembuatan papan semen adalah bambu berumur muda.

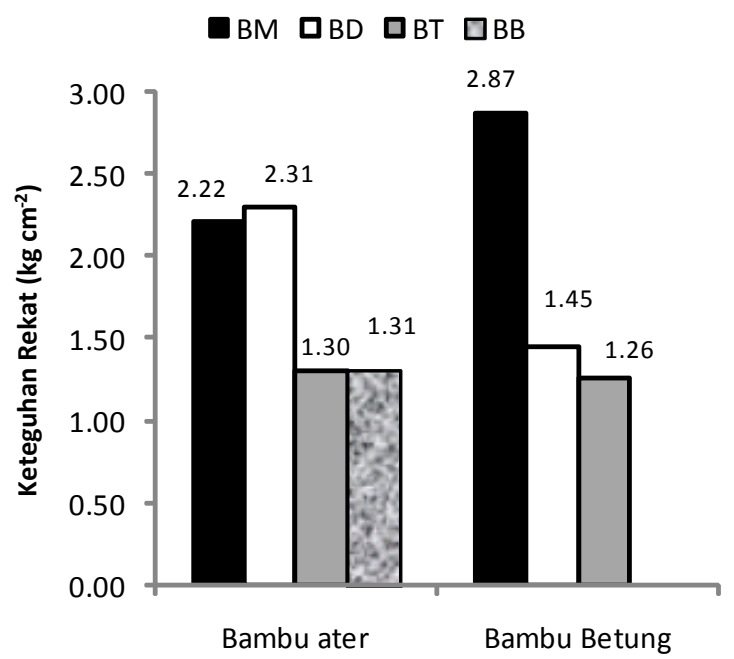

Gambar 4. Keteguhan rekat papan semen

Nilai keteguhan patah papan semen yang terbuat dari bambu ater relatif setara dengan papan semen dari bambu betung. Akan tetapi, kekakuan papan semen dari bambu ater cenderung lebih rendah dibandingkan dengan papan semen dari bambu betung. Data tersebut mengindikasikan bahwa bambu betung memiliki MOE yang lebih baik dibandingkan dengan bambu ater.

Parameter keteguhan rekat sebagaimana disajikan pada Gambar 4 menunjukkan bahwa keteguhan rekat papan semen memiliki kecenderungan yang sama dengan MOE-nya, di mana nilai keteguhan rekatnya cenderung menurun seiring dengan pertambahan usia bambu. Bambu betung memiliki nilai keteguhan rekat yang lebih tinggi dibandingkan dengan bambu ater pada papan semen yang terbuat dari bambu berumur muda. Akan tetapi keteguhan rekat papan semen dari bambu ater cenderung lebih rendah dibandingkan dengan papan semen dari bambu betung pada bambu berumur dewasa, sementara pada umur tua, keteguhan rekat relatif setara. Keteguhan rekat papan semen dari bambu betung menurun secara drastis dari bambu berumur muda ke bambu berumur dewasa maupun tua, sementara pada papan semen dari bambu ater, keteguhan rekatnya relatif setara antara papan semen dari bambu berumur muda dengan bambu dewasa. Untuk bambu ater, keteguhan rekatnya menurun secara drastis dari bambu dewasa ke bambu yang berumur tua.

Stabilitas dimensi dan keteguhan patah papan semen dari bambu bekas pakai cenderung lebih tinggi dibandingkan dengan papan semen dari 
bambu segar, sementara MOE-nya cenderung lebih rendah. Stabilitas dimensi dan keteguhan patah yang tinggi pada bambu bekas pakai disebabkan oleh penurunan kadar pati pada saat bambu digunakan atau telah ditebang dalam jangka waktu yang lama (Moslemi, 1989). Bambu yang digunakan sebagai scaffolding biasanya digunakan dua sampai tiga kali sebelum dibuang. Dalam penelitian ini, kami menggunakan bambu bekas dari scaffolding yang telah digunakan dua kali. Hal ini mengindikasikan bahwa bambu tersebut telah dipanen beberapa bulan sebelumnya.

Papan semen dari bambu betung bekas pakai tidak dibuat dalam penelitian ini karena jenis bambu betung ini biasanya digunakan bukan untuk tujuan temporer seperti scaffolding atau penggunaan lainnya pada bambu ater yang bersifat sementara. Karena itu tidak tersedia bambu bekas untuk jenis bambu betung. Secara umum, papan semen yang terbuat dari bambu bekas memiliki karakteristik yang setara dengan papan semen yang terbuat dari bambu segar. Dengan demikian, penggunaan bambu bekas sebagai bahan baku pembuatan papan semen sangat memungkinkan.

\section{KESIMPULAN}

Bambu ater dan bambu betung berumur muda lebih sesuai digunakan sebagai bahan baku pembuatan papan semen, karena sifat fisik dan mekanisnya cenderung lebih baik dibandingkan dengan papan semen yang terbuat dari bambu kelompok umur dewasa maupun tua. Oleh karena panjangnya waktu yang dibutuhkan antara waktu memanen dengan pada saat bambu tersebut dibudidayakan, maka penggunaan bambu muda juga akan sangat menguntungkan karena dapat mempersingkat periode panen bambu. Penggunaan bambu bekas pakai sebagai bahan baku pembuatan papan semen tidak memiliki pengaruh negatif terhadap karakteristik papan semen yang dihasilkannya.

\section{DAFTAR PUSTAKA}

[JSA] Japanese Standards Association. 2003a. Cement Board. Japanese Industrial Standar (JIS) A 5417-2003. Japan.

[JSA] Japanese Standards Association. 2003b. Particleboards. Japanese Industrial Standar (JIS) A 5908-2003. Japan.

Kementerian Pekerjaan Umum. 2013. Statistik Semen Nasional. Jakarta.

Ling, F. M., H. Yamauchi, O.R. Pulido, Y. Tamura, H. Sasaki and S. Kawai. 2000. Manufacture of Cemen-bonded Board from Wood and Other Lignocellulosic Materials: Proceeding of Workshop Wood-Cement Composites in the Asia-Pacific Region. Editor: PD Evans. Canberra, Australia, 10 Desember 2000.

Moslemi, A. A. 1989. Wood-Cement Panel Products: Coming Age. Proceeding of Fiber and Particleboards Bonded with Inorganic Binder Conference. Forest Products Research Society, Madison, Wisconsin, USA.

Muin, M., Suhasman, N. P. Oka, B. Putranto, Baharuddin dan S. Millang. 2006. Pengembangan Potensi dan Pemanfaatan Bambu sebagai Bahan Baku Konstruksi dan Industri di Sulawesi Selatan. Badan Penelitian dan Pengembangan Daerah. Makassar. 73p.

Suhasman, M. Y. Massijaya and Y. S. Hadi. 2005. The Effect of Face and Back Layer Types on Composite Board Quality. Proceedings of the 6th International Wood Science Symposium. Bali, Indonesia. August 29-31, 2005. Pp. 241-247.

Sukartana P, R. Rushelia, I. M. Sulastiningsih. 2000. Resistance of Bamboo-Cement Boards to Subterranean Termite Coptotermes gestroy Wasmann. Proceeding of Workshop Wood-Cement Composites in the Asia-Pacific Region. Editor : PD Evans. Canberra, Australia, 10 Desember 2000.

Sulastiningsih I M, N Hadjib, S Murdjoko, S Kawai. 2000. The Effect of Bamboo : Cement Ratio and Magnesium Chloride $\left(\mathrm{MgCl}_{2}\right)$ Content on the Properties of BambooCement Boards. Proceeding of Workshop Wood-Cement Composites in the Asia-Pacific Region. Editor : PD Evans. Canberra, Australia, 10 Desember 2000.

Widjaja, E. A. 1980. Indonesia (Country report on bamboo research and development). In: Lessard, G. \& A. Chouinard. Bamboo Research in Asia: 63-68. 